\title{
Amorphous-Nanocrystalline Transition in Silicon Thin Films Obtained by Argon Diluted Silane PECVD
}

\author{
Rachid Amrani $^{1,2^{*}}$, Frederic Pichot ${ }^{1}$, Larbi Chahed ${ }^{2}$, Yvan Cuminal ${ }^{1}$ \\ ${ }^{1}$ Université Montpellier II, Place Eugène Bataillon Montpellier, Montpellier, France \\ ${ }^{2}$ Département de Physique, Université d'Oran ES-Sénia, Oran, Algérie \\ Email: ${ }^{*}$ rachidamrani2002@yahoo.fr, rachid.amrani@ies.univ-montp2.fr
}

Received October 4, 2012; revised November 8, 2012; accepted November 22, 2012

\begin{abstract}
The Plasma-Enhanced Chemical Vapor Deposition (PECVD) method is widely used compared to other methods to deposit hydrogenated silicon Si:H. In this work, a systematic variation of deposition parameters was done to study the sensitivities and the effects of these parameters on the intrinsic layer material properties. Samples were deposited with 13.56 MHZ PECVD through decomposition of silane diluted with argon. Undoped samples depositions were made in this experiment in order to obtain the transition from the amorphous to nanocrystalline phase materials. The substrate temperature was fixed at $200^{\circ} \mathrm{C}$. The influence of depositions parameters on the optical proprieties of the thin films was studied by UV-Vis-NIR spectroscopy. The structural evolution was also studied by Raman spectroscopy and X-ray diffraction (XRD). The structural evolution studies show that beyond $200 \mathrm{~W}$ radio frequency power value, we observed an amorphous-nanocrystalline transition, with an increase in crystalline fraction by increasing RF power and working pressure. The deposition rates are found in the range $6-10 \AA / \mathrm{s}$. A correlation between structural and optical properties has been found and discussed.
\end{abstract}

Keywords: Silicon Thin Film; PECVD; Amorphous-Nanocrystalline Transition; Deposition Rate; Powders; Argon

\section{Introduction}

The hydrogenated nanocrystalline silicon (nc-Si:H) has gained much attention over amorphous silicon $(\mathrm{a}-\mathrm{Si}: \mathrm{H})$. The light-induced degradation of a-Si:H, also named Stabler-Wronski effect $[1,2]$, has been a major bottleneck since it was observed in practical device applications such as thin film solar cells. Several deposition methods have been used to prepare device quality films. These include Hot Wire-CVD (chemical vapor deposition) [3], Electron Cyclotron Resonance-CVD [4], conventional Plasma-Enhanced-CVD (PECVD) [5], Very High Frequency Plasma Enhanced-CVD [6], Microwave-CVD [7] and Radio-Frequency Magnetron Sputtering of crystalline silicon target [8]. Among these, only PECVD has been established for industrial applications.

However, the device quality nc-Si:H films prepared by PECVD method with silane hydrogen mixture, at optimized deposition parameters show lower deposition rate $(0.4-3 \AA / s)$.

Another problem with this kind of method is the powders formation during the film growth. A general study of powders formation has been performed by Dorier et al. [9-11] as a function of silane dilution in argon, helium or

${ }^{*}$ Corresponding author. hydrogen in PECVD system. Dorier [12] compared the powder appearance time value $t_{a}$ versus gas used for silane dilution; argon, helium or hydrogen. As shown in Figure 1, it is interesting to note that a strong difference is evidenced when comparing between these three situations. $t_{a}$ decreases when silane is diluted in argon while helium and hydrogen dilution lead to the inverse effect. The probability that initial clusters have a chance to form small particles being stored in the plasma is enhanced for argon dilution and reduced for helium or hydrogen dilution.

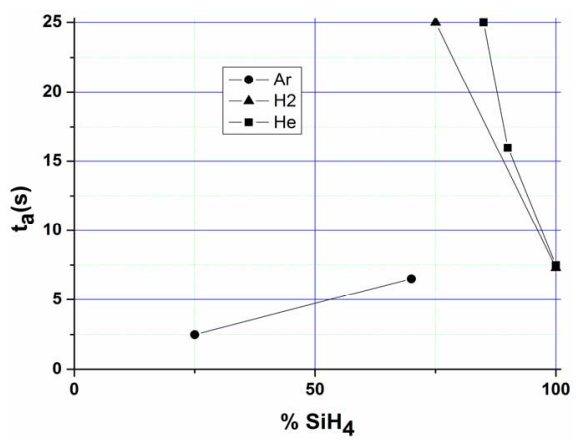

Figure 1. Particle appearance time as a function of silane partial pressure in silane mixtures with argon, helium or hydrogen [12]. 
When silane is diluted with hydrogen, it is well known that growth rate is reduced, with simultaneous trends to form nanocrystalline structure in place of a-Si:H. The lower deposition rates increase the process operation time and hence the production cost.

In this work, the $\mathrm{Si}: \mathrm{H}$ thin films were deposited in a conventional PECVD system, using argon silane mixture. By Raman and XRD spectroscopy, the structural evolution was studied. The optical characterization for these films was also appraised by UV-Visible-NIR spectrophotometer.

\section{Experimental Procedure}

Samples were deposited in a Radio-Frequency (RF) 13.56 (MHZ) PECVD chamber. The electrode area was $350 \mathrm{~cm}^{2}$ and the distance between electrodes $1.2 \mathrm{~cm}$. The mixed precursor gases were ultrahigh purity silane $\left(\mathrm{SiH}_{4}\right)$ and argon (Ar). The dilution ratio (the argon to silane flow ratio) was fixed at 25 during all the processes. The deposition pressure varied from 400 mTorr to 1400 mTorr, at various RF powers $(50,100,200$ and $250 \mathrm{~W})$ and substrate temperature was fixed at $200^{\circ} \mathrm{C}$.

Before the deposition, all glass substrates were cleaned strictly following a standard procedure to ensure a good adhesion between the substrate and the $\mathrm{Si}: \mathrm{H}$ layer. Raman spectra were recorded with micro-Raman spectroscopy (Jobin Yvon Horibra LABRAM-HR). The spectrometer has backscattering geometry for detection of Raman spectrum with the resolution of $1 \mathrm{~cm}^{-1}$. The excitation source was $473.5 \mathrm{~nm}$ line of Argon laser. The power of the Raman laser was kept about $2 \mathrm{~mW}$ to avoid laser induced crystallization on the films. Low angle X-ray diffraction pattern was obtained by X-ray diffractometer using $\mathrm{CuK} \alpha$ line $(\lambda=1.54056 \AA)$. Thickness and refractive index were determined by UV-Vis-NIR spectroscopy using the envelope method [13,14]. The average band gap $E_{M}$ was estimated using the procedure followed by Wemple et al. [15].

\section{Results and discussion}

The variation of deposition rate plotted as a function of process pressure is shown in Figure 2. It shows that, the increase of RF power increases the deposition rate. It is seen also that the deposition rate increases from $\sim 6 \AA / \mathrm{s}$ to $\sim 7.5 \AA / \mathrm{s}$, when the process pressure increases from 400 mTorr to 1000 mTorr. With further increase in process pressure to 1400 mTorr, the deposition rate decreases. Thus, with increase in process pressure the impingement rate of silane on the plasma increases. As a result, the number of film-forming radicals and hence the deposition rate increases. With further increase in process pressure the supply of film-forming radicals also increases. However, the powders electrostatically trapped in the plasma prevent the films from growth. So, in order to obtain a deposition without dust trapped in the plasma, the process pressure must be below $1000 \mathrm{mTorr}$.

The crystallinity of the films was studied by low angle X-ray diffraction (XRD). XRD patterns of two typical samples at the same pressure (1400 mTorr) with different RF power are shown in Figure 3. At $100 \mathrm{~W}$ RF power, no crystal grains are detected in this sample; there is no apparent structural evolution in the thin films.

When RF power reaches $200 \mathrm{~W}$, diffraction peaks arise. With the increase of RF power, there appear three peaks symbolizing three different silicon crystalline orientations. Also, the growth of grains in the thin films is multi-oriented. The average crystallite size $\left(\mathrm{d}_{\mathrm{XRD}}\right)$ can be estimated using the classical Scherrer's formula [16]. The estimated average crystallite size $d_{\text {XRD }}$ obtained for the films deposited at RF power $200 \mathrm{~W}$ and at working pressure of 800, 1000, 1200 and 1400 mTorr are 7.1, 9.5, 12.2 and $15.1 \mathrm{~nm}$, respectively.

Micro-Raman spectroscopy has been widely used as a powerful technique to characterize deposited thin layers. It can elucidate the amorphous and crystalline phase. Figure 4 shows Raman spectra of Si:H films deposited at various process pressure and RF power.

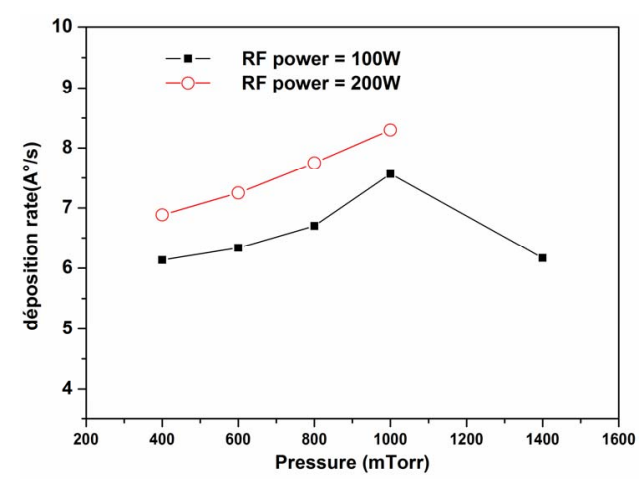

Figure 2. Variation of deposition rate as a function of process pressure and RF power for $\mathrm{Si}: \mathrm{H}$ films deposited by PECVD.

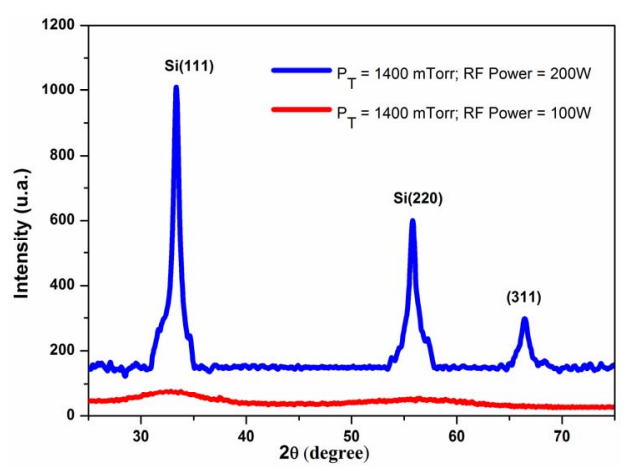

Figure 3. Low angle X-ray diffraction pattern of two typical samples deposited at the same pressure (1400 mTorr) with different RF power. 
For samples deposited below $200 \mathrm{~W}$ RF power, the TO band is composed by only a broad peak located around $480 \mathrm{~cm}^{-1}$, characteristic of a completely amorphous structure. Beyond $200 \mathrm{~W}$ RF power and beyond 800 mTorr pressure deposition, the TO band can be correctly fitted using three Gaussian components centered around 480, 510 and $520 \mathrm{~cm}^{-1}$, suggesting the presence in these films a mixture of amorphous as well as crystalline structure with different grain sizes. The estimated crystalline volume fraction Fc $[17,18]$ and crystallite size $d_{\text {Raman }}[19]$ in the films are also indicated in Figure 4. For nanocrystalline materials, with increase process pressure and RF power, both, $\mathrm{Fc}$ and $\mathrm{d}_{\text {Raman }}$ in the films increase. For samples deposited at $200 \mathrm{~W}$, Fc increases from $21 \%$ to $90 \%$ and $\mathrm{d}_{\text {Raman }}$ increases from $6.4 \mathrm{~nm}$ to $16.2 \mathrm{~nm}$, when the process pressure increases from $800 \mathrm{mTorr}$ to 1400 mTorr.

Film particle sizes measured by XRD method turned out significant difference with those measured by Raman method. The difference can be due to the different detection sensitivity of characterization techniques. However, it is important to note that the crystallite sizes determined by both techniques at various process pressure show same trend. Therefore, for nanocrystalline samples, with increase in process pressure, the grain size increases.

To achieve a better understanding of the optical proprieties of $\mathrm{Si}: \mathrm{H}$, the optical transmission of films was
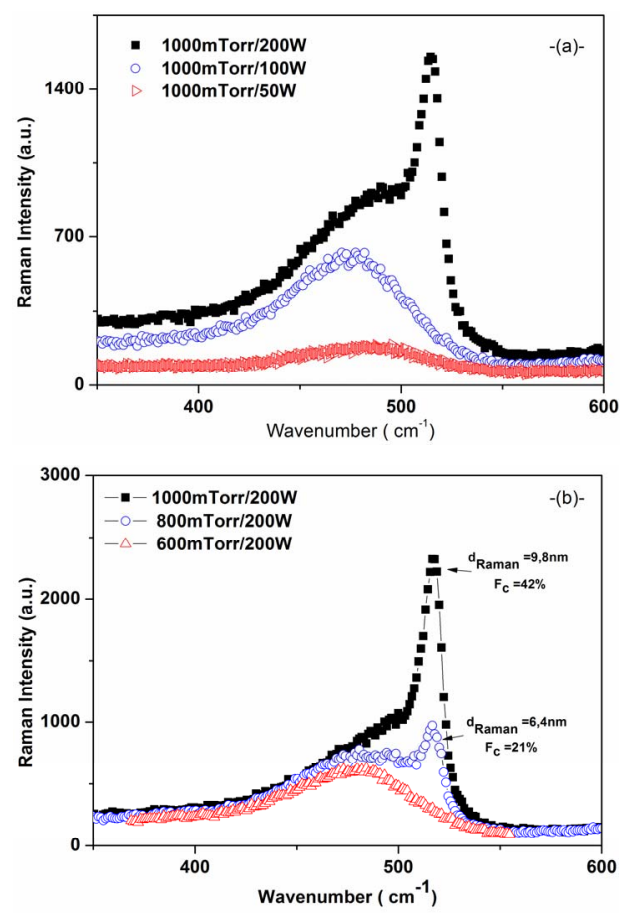

Figure 4. Typical Raman spectra obtained in the TO-like mode, for films deposited (a): with deposition pressure of 1000 mTorr and varying $R F$ power $(50,100,200$ and 250 $\mathrm{W})$; and (b): RF power $200 \mathrm{~W}$ and varying pressure (600, 800, 1000 mTorr). measured by UV-Vis-NIR spectrophotometer. The films thickness and the refraction indexes were determined using the method proposed by Swanepoel [13].

Figure 5 shows the variation of static refractive index as a function of deposition parameters. The refractive index increases when the working pressure increases. Also, the refractive index decreases when RF power increases.

The refraction index is an important parameter, since it could be linked to the material density $[8,20]$. Indeed, a good material is compact, i.e. it presents a minimum of micro-cavities.

Detailed analysis of the refractive index spectra were performed using the model suggested by Wemple and Didomenico [15]. At energies below than of the optical bandgap, the refractive index is related to the square of the photon energy $(\hbar \omega)^{2}$ by:

$$
n^{2}(\hbar \omega)=1+\frac{E_{M} E_{D}}{E_{M}^{2}-(\hbar \omega)^{2}}
$$

The plot of $1 /\left[\mathrm{n}^{2}(\hbar \omega)-1\right]$ versus $(\hbar \omega)^{2}$ allows the determination of the average gap $E_{M}$, and the dispersion energy $E_{D}$.

Figure 6 shows that all samples deposited at $100 \mathrm{~W}$ RF power have a high average gap value $E_{M}$, which exhibits a completely amorphous structure. But for films grown at

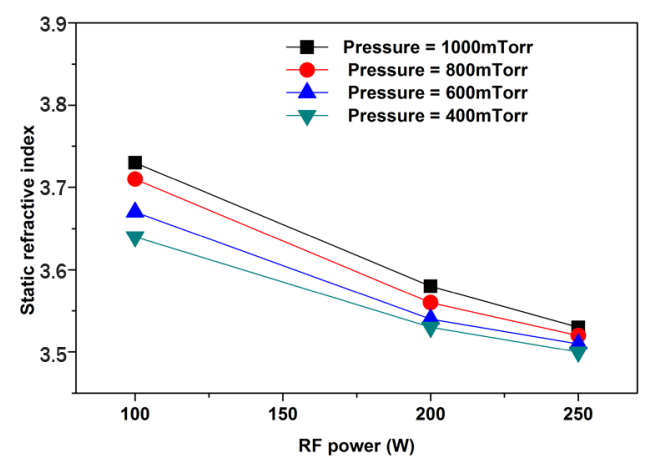

Figure 5. Variation of static refractive index for samples deposited at different process pressure and RF power.

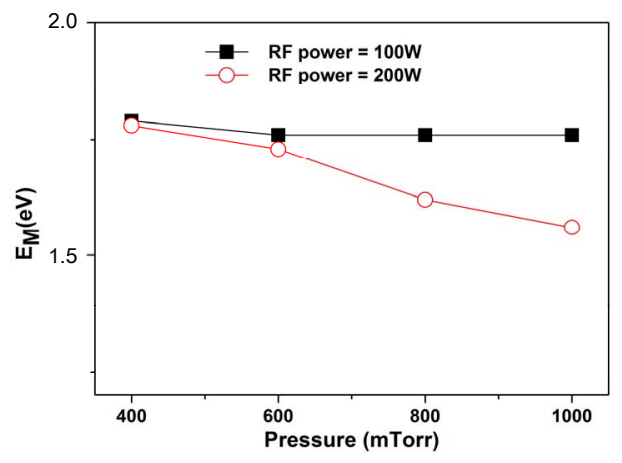

Figure 6. Variation of average band gap for $\mathrm{Si}: \mathrm{H}$ films deposited by PECVD as a function of process pressure and RF power. 
$200 \mathrm{~W}$ and beyond $800 \mathrm{mTorr}, E_{M}$ decreases considerably. This confirms once again, that beyond these deposition parameters, an amorphous-nanocrystalline transition is observed.

The RF bias voltage is an important deposition parameter of nc-Si:H films. During the growth, the RF bias has a decisive effect on the energy and natures of $\left(\mathrm{SiH}_{\mathrm{n}}\right)$ species [19]. The appropriate bias may control the reaction rate at the gas-substrate interface, so as to promote the nucleation rate, and enhance the densification of nanocrystallites in the growing films. He et al. demonstrate also, that bias voltage controls the crystalline fraction for nc-Si:H samples [19]. In this work, and at certain deposition parameters, the bias varies. For power more than $200 \mathrm{~W}$ and pressure below $800 \mathrm{mTorr}$, RF bias increases from $3 \mathrm{~V}$ to $80 \mathrm{~V}$, after a few minutes for the beginning of the deposition process. The reflect RF power is also an important parameter. After a specific deposition time $(\sim 10 \mathrm{~min})$, the reflect power increases, and in consequence the real power deposition decreases. To resolve the effects of RF bias and RF power reflect values, samples were deposited with layer by layer (LBL) deposition method.

\section{Conclusion}

As conclusion, we have proved that the formation of powders in Silane-Argon plasma, initially considered as a drawback, can be exploited to produce nanocrystalline silicon particles. We have shown that hydrogenated nanocrystalline silicon (nc-Si:H) films can be prepared from silane argon mixture without hydrogen dilution at high deposition rates $(\sim 10 \AA / \mathrm{s})$ and at low substrate temperature $\left(200^{\circ} \mathrm{C}\right)$ using PECVD method. The structural evolution studies show that beyond $200 \mathrm{~W}$ RF power and beyond 800 mTorr pressure deposition conditions, we observed an amorphous-nanocrystalline transition. From the present study it has been concluded that the process pressure and RF power are the key process parameters to induce the crystallinity in the $\mathrm{Si}: \mathrm{H}$ films grown by PECVD method. From materials and devices application, especially, photovoltaic devices application, nanocrystalline silicon produced at low temperature in silane plasma, open the way to new applications, like the deposition on flexible substrate.

\section{Acknowledgements}

The authors would like to thank D. Bourgogne for Raman experiments assistance and B. Fraisse for the X-ray diffraction measurements. This work is kindly supported by Averroes Program.

\section{REFERENCES}

[1] W. E. Spear and P. G. LeComber, "Subtitutional Doping of Amorphous Silicon," Solid State Communications, Vol. 17, No. 9, 1975, pp. 1193-1196. doi:10.1016/0038-1098(75)90284-7

[2] D. L. Staebler and C. R. Wronki, "Reversible Conductivity Changes in Discharge Produced Amorphous Si," Applied Physical Letters, Vol. 31, No. 4, 1977, p. 292. doi:10.1063/1.89674

[3] H. Li, R. H. Franken, R. L. Stolk, C. H. M. van der Werf, J. K. Rath and R. E. I. Schropp, "Controlling the Quality of Nanocrystalline Silicon Made by Hot-Wire Chemical Vapor Deposition by Using a Reverse $\mathrm{H}_{2}$ Profiling Technique," Journal of Non-Crystalline Solids, Vol. 354, No. 19-25, 2008, pp. 2087-2091.

[4] M. Birkholz, B. Selle, E. Conrad, K. Lips and W. Fuhs, "Evolution of Structure in Thin Microcrystalline Silicon Films Grown by Electron-Cyclotron Resonance Chemical Vapor Deposition," Journal of Applied Physics, Vol. 88, No. 7, 2000, pp. 4376-4379. doi:10.1063/1.1289783

[5] B. Rech, T. Roschek, J. Müller, S. Wieder and H. Wagner, "Amorphous and Microcrystalline Silicon Solar Cells Prepared at High Deposition Rates Using RF (13.56 MHz) Plasma Excitation Frequencies," Solar Energy Materials and Solar Cells, Vol. 66, No. 1-4, 2001, pp. 267-273. doi:10.1016/S0927-0248(00)00183-5

[6] Y. Mai, S. Klein, R. Carius, L. Houben, X. Geng and F. Finger, "Improvement of Open Circuit Voltage in Microcrystalline Silicon Solar Cells Using Hot Wire Buffer Layers," Journal of Non-Crystalline Solids, Vol. 352, No. 9-20, 2006, pp. 1859-1862.

[7] M. van Veen, C. van der Werf and R. Schropp, "Tandem Solar Cells Deposited Using Hot-Wire Chemical Vapor Deposition," Journal of Non-Crystalline Solids, Vol. 338340, No. 1, 2004, pp. 655-658. doi:10.1016/j.jnoncrysol.2004.03.071

[8] R. Amrani, D. Benlekehal, R. Baghdad, D. Senouci, A. Zeinert, K. Zellama, L. Chahed, J. D. Sib and Y. Bouizem, "Low-Temperature Growth of Nanocrystalline Silicon Films Prepared by RF Magnetron Sputtering: Structural and Optical Studies," Journal of Non-Crystalline Solids, Vol. 354, No. 19-25, 2008, pp. 2291-2295. doi:10.1016/j.jnoncrysol.2007.10.044

[9] J. L. Dorier, C. Hollenstein, A. A. Howling and U. Kroll, "Powder Dynamics in Very High Frequency Silane Plasmas," Journal of Vacuum Science \& Technology, Vol. A10, No. 4, 1992, pp. 1048-1052. doi:10.1116/1.578200

[10] J. L. Dorier, C. Hollenstein and A. A. Howling, "Spatiotemporal Powder Formation and Trapping in Radio Frequency Silane Plasmas Using Two-Dimensional Polarization-Sensitive Laser Scattering," Journal of Vacuum Science \& Technology, Vol. A13, No. 3, 1995, pp. 918926. doi:10.1116/1.579852

[11] A. A. Howling, J. L. Dorier, C. Hollenstein, U. Kroll and F. Finger, "Frequency Effects in Silane Plasmas for Plasma Enhanced Chemical Vapor Deposition," Journal of Vacuum Science \& Technology, A10, No. 4, 1992, pp. 1080-1085. doi:10.1116/1.578205

[12] J. L. Dorier,"Genèse, Croissance et Conséquences de Particules Dans les Plasmas en Silane à Basse Pression et Basse Température,” Ph.D. Thesis, E.P.F.L, Switzerland, 
1996.

[13] R. Swanpoel, "Determination of the Thickness and Optical Constants of Amorphous Silicon," Journal of Physics E: Scientific Instruments, Vol. 16, No. 12, 1983, pp. 12141222. doi:10.1088/0022-3735/16/12/023

[14] J. C. Manifacier, J. Gasiot and J. P. Fillard, “A Simple Method for the Determination of the Optical Constants n, $\mathrm{k}$ and the Thickness of a Weakly Absorbing Thin Film," Journal of Physics E: Scientific Instruments, Vol. 9, No. 11, 1976, pp. 1002-1004. doi:10.1088/0022-3735/9/11/032

[15] S. H. Wemple and M. Didomenico, "Behavior of the Electronic Dielectric Constant in Covalent and Ionic Materials," Physical Review B, Vol. 3, No. 4, 1971, pp. 13381351. doi:10.1103/PhysRevB.3.1338

[16] P. Scherrer, "Bestimmung der Grösse und Derinneren Struktur von Kolloidteilchen Mittels Röntgenstrahlen," Nachrichten von der Gesellschaft der Wissenschaften zu Göttingen, Mathematisch-Physikalische Klasse, Vol. 26,
No. 1, 1918, pp. 98-100.

[17] G. Yue, J. D. Lorentzien, J. Lin, D. Han and Q. Wang, "Photoluminescence and Raman Studies in Thin-Film Materials: Transition from Amorphous to Microcrystalline Silicon," Journal of Applied Physical Letters, Vol. 75, No. 4, 1999, pp. 492-494. doi:10.1063/1.124426

[18] D. Beeman, R. Tsu and M. F. Thorpe, "Structural Information from the Raman Spectrum of Amorphous Silicon," Physical Review B, Vol. 32, No. 2, 1985, pp. 874878. doi:10.1103/PhysRevB.32.874

[19] Y. He, C. Yin, G. Cheng, L. Wang, X. Liu and G. H. Hu, "The Structure and Properties of Nanosize Crystalline Silicon Films," Journal of Applied Physics, Vol. 75, No. 2, 1994, pp. 797-803. doi:10.1063/1.356432

[20] E. C. Freeman and W. Paul, "Optical Constants of rf Sputtered Hydrogenated Amorphous Si," Physical Review $B$, Vol. 20, No. 1, 1979, pp. 716-728. doi:10.1103/PhysRevB.20.716 